\title{
Cell Volume per Nucleus in Haploid and Diploid Strains of Aspergillus nidulans
}

\author{
By A. J. CLUTTERBUCK \\ Department of Genetics, University of Glasgow, Glasgow, Scotland
}

(Accepted for publication 9 October 1968)

\begin{abstract}
SUMMARY
Diploid conidiospores of Aspergillus nidulans are uninucleate and have twice the volume of haploid conidiospores. On the other hand, the hyphae are coenocytic, and it has been found that the dimensions of the hyphal cell are unaffected by ploidy but that diploid cells have half as many nuclei as haploid ones. It is concluded from this that both cessation of growth in cells of fixed size and the timing of mitoses in coencytes are determined by a critical volume of cytoplasm per genome, rather than per nucleus.

In the conidial apparatus, the dimensions of the coenocytic conidiophore, like the hyphae, are unaffected by ploidy, while the uninucleate sterigmata are larger in the diploid. In the case of the primary sterigmata, however, the volume in the diploid is less than twice that in the haploid, suggesting that the mechanism controlling cytoplasmic volume is not fully operative at this stage.
\end{abstract}

\section{INTRODUCTION}

Cell volume is frequently proportional to the DNA content of the cell nucleus: this can be seen in polyploid, multinucleate or polytene tissues (List, I963), in comparisons of members of a polyploid series (Noggle, 1946), or in inter-species comparisons (Commoner, I964; Yčas, Sugita \& Bensam, 1965).

A relationship between cell size and the initiation of mitosis is also well known, particularly from the experiments of Hartmann (1928) and Prescott (1956) on Amoeba, and the significance of this has been discussed in a number of reviews (Swann, I957; Mazia, 196r; Yčas et al. 1965).

The Ascomycete, Aspergillus nidulans, contains both coenocytic hyphae, and, in the conidial apparatus, uninucleate cells. Comparison of haploids and diploids in this system shows a close connexion between the above two sets of relationships, since in the coenocytes, cell volume is independent of ploidy, but the number of nuclei per unit volume is not. The special feature of this system is that in a constant growing coenocyte the only feature that can regulate the number of nuclei per unit volume is the frequency of mitosis. In the uninucleate conidia, on the other hand, this regulation depends on the timing of the cessation of growth, and here again, the cell volume is proportional to ploidy and DNA content (Heagy \& Roper, 1952; Pontecorvo, Roper, Hemmons, Macdonald \& Bufton, I953).

The transition between the coenocytic and uninucleate situations occurs in the sterigmata, and examination of these suggests that differences in ploidy are expressed as differences in cell volume only at certain stages of the cell cycle. 


\section{METHODS}

Strains. Strains were all derived from the stocks of Aspergillus nidulans in the Department of Genetics, Glasgow University (Pontecorvo et al. 1953; Käfer, 1958). Hyphal measurements were made on the haploid: $y$; w3;pyro4 and the diploid:

$$
\frac{+\quad+\text { biI }}{\text { pabaI } y+} \frac{\text { w3 }}{+} \frac{\text { pyro4 }}{\text { pyro4 }} \text {. }
$$

Measurements of conidial apparatus were made on the haploid: bir, and the diploid:

$$
\frac{\text { pabaI } y \text { biI }}{+\quad+b i I} \frac{+}{w 2} \frac{+}{\text { orn2 }} \text {. }
$$

( $w=$ white conidia, $y=$ yellow conidia $; b i$, pyro, paba, orn $=$ requirements for biotin, pyridoxine, $p$-aminobenzoic acid, and ornithine respectively).

The haploid and diploid strains to be compared thus had the same nutritional requirements (pyridoxine in the first case, biotin in the second), and the strains for conidial apparatus measurements were both green, since all the markers used are recessive. The diploids were obtained by the method of Roper (1952), however, so they are necessarily heterozygous for nutritional markers not present in the haploids.

Media. The minimal medium of Pontecorvo et al. (1953) was used, supplemented with $550 \mu \mathrm{g}$./1. pyridoxine or $22 \mu \mathrm{g}$./1. biotin as appropriate. Cultures were incubated at $37^{\circ}$.

Microscopy. Nuclei were examined by means of acridine fluorescence (Anderson, Armstrong \& Niven, 1959). Adaptation of this technique to Aspergillus was suggested by photographs of other acridine stained fungi (Anderson, unpublished work). Details of the present slide culture and staining technique have been given before (Clutterbuck \& Roper, 1966).

Measurements of hyphae (Table I) were taken from camera-lucida drawings of hyphae at the colony growth front. Hyphal diameter was measured on a scale that read directly in terms of cross-sectional area, on the assumption that the hyphae are cylindrical. Material for measurements of the conidial apparatus (Tables 2 and 4 ) was grown on ordinary agar plates. Measurements of conidiophore length and conidial column diameter were made on material wetted with xylene; for other measurements alcohol was used. The length of primary sterigmata was measured on heads bearing primary and secondary sterigmata only, while the combined length of primary and secondary sterigmata was measured on heads bearing the first conidia. Measurements were made with a micrometer eyepiece and only one measurement was made on any head.

The diameter of the vesicle and the spacing of the primary sterigmata were measured on camera-lucida drawings of conidiophores from old cultures which had been shaken with $0 . \mathrm{I} \%(\mathrm{v} / \mathrm{v})$ Tween 80 (Koch-Light) detergent solution to wash off conidia and sterigmata. The drawings included the holes in the vesicle marking the former positions of the sterigmata, and the area of a triangle between the three holes most directly facing the microscope objective was measured on each drawing. This triangle is referred to as the 'sterigmata triangle' (see Fig. $\mathrm{I}, f$ ).

For fluorescence microscopy of sterigmata, pieces of a colony on agar, taken from the colony edge and therefore bearing developing conidial heads, were placed, face 
downwards, on microscope slides kept at $-20^{\circ}$. As soon as the surface of the colony had frozen on to the slide, the rest of the agar was removed and the slide was freezedried. The preparation was fixed and stained as for hyphal fluorescence.

\section{RESULTS AND DISCUSSION}

Hyphae. Studies were confined to the terminal cell (i.e. from the hyphal tip to the first septum) of each hypha since this cell is largely independent, at least as far as growth is concerned, of the older parts of the colony (Clutterbuck \& Roper, I966). Side branches of the cell, where these occurred, were ignored. The results, given in Table $\mathrm{I}$, show that the dimensions of the terminal cell are very similar in haploids and

Table I. The dimensions and numbers of nuclei of the terminal hyphal cells of Aspergillus nidulans

Figures are means with standard errors.

\begin{tabular}{|c|c|c|c|c|c|}
\hline $\begin{array}{l}\text { Number } \\
\text { of cells }\end{array}$ & $\begin{array}{l}\text { Length } \\
\qquad(\mu)\end{array}$ & $\begin{array}{l}\text { Cross- } \\
\text { sectional } \\
\text { area }\left(\mu^{2}\right)\end{array}$ & $\begin{array}{l}\text { Volume } \\
\qquad\left(\mu^{3}\right)\end{array}$ & $\begin{array}{c}\text { Number of } \\
\text { nuclei }\end{array}$ & $\begin{array}{c}\text { Volume per } \\
\text { nucleus } \\
\left(\mu^{3}\right)\end{array}$ \\
\hline Hapl & $451 \pm 13$ & $12.9 \pm 0.4$ & $5715 \pm 296$ & $66 \cdot 6 \pm 2 \cdot 4$ & $88 \cdot 6 \pm 3 \cdot 2$ \\
\hline 52 & $433 \pm$ & II $\cdot 8 \pm 0 \cdot 4$ & $5169 \pm 236$ & $3 I \cdot 7 \pm I \cdot 3$ & $I 66 \cdot 3 \pm 6 \cdot I$ \\
\hline $\begin{array}{l}\text { Ratio: } \\
\text { diploid/haploid } \\
\text { ' } t \text { ' test: } \\
\text { diploid }=\text { haploid } \\
\text { ' } t \text { ' test: } \\
\text { diploid }=2 \times \text { haploid }\end{array}$ & $\begin{array}{c}0.96 \\
t=\mathrm{I} \cdot 02 \\
\text { Non-sig. }\end{array}$ & $\begin{array}{c}0.9 \mathrm{I} \\
t=\mathrm{I} \cdot 90 \\
\text { Non-sig. }\end{array}$ & $\begin{array}{c}0.90 \\
t=\mathrm{I} \cdot 44 \\
\text { Non-sig. } \\
-\end{array}$ & $\begin{array}{l}\quad 2 \cdot 10 \\
t=12 \cdot 7 \\
P<0 \cdot 001 \\
t=\mathrm{I} \cdot 06 \\
\text { Non-sig. }\end{array}$ & $\begin{array}{l}\quad \mathrm{I} \cdot 88 \\
t=\mathrm{II} \cdot 4 \\
P<0 \cdot 00 \mathrm{I} \\
t=\mathrm{I} \cdot 45 \\
\text { Non-sig. }\end{array}$ \\
\hline
\end{tabular}

diploids. The numbers of nuclei in the two types of cell, however, are very different, with the result that the volume of cytoplasm per nucleus in the diploid is approximately twice that in the haploid. This means that the hyphae of Aspergillus nidulans are similar to the multinucleate conidia of $A$. sojae (Ishitani, Uchida \& Ikeda, 1956) in that constancy of cytoplasm per genome in haploids and diploids is not obtained by alteration of cell size as in uninucleate cells, but by alteration of number of nuclei in cells of the same mean volume. Haploid and diploid hyphae of $\boldsymbol{A}$. nidulans elongate at a similar rate (c. 210 $\mu / \mathrm{hr}$ under the conditions used), so that establishment of a double volume of cytoplasm per nucleus in the diploid requires a reduced frequency of mitosis. It has long been known that in any continuously growing organism a critical volume of cytoplasm, or some particular feature of it, triggers mitosis (see Swann, 1957, and Mazia, I96I, for reviews). The present work stresses that it is a critical volume of cytoplasm per genome that is the trigger, just as in uninucleate cells of determinate growth (of which the conidia of $A$. nidulans are examples) a critical volume of cytoplasm per genome signals the cessation of growth. Another way of expressing these results is to say that in haploid and diploid hyphae the dimensions of the cell and the volume of cytoplasm per genome are all constant, it is only the packaging of genomes into nuclei that differs. It should be noted that once the characteristic volume of cytoplasm per nucleus is established in each strain, haploid or diploid, the rate of mitosis will also be the same, since in both types of strain, doubling of the nuclei must correspond with the doubling time of the cytoplasm. It is only in adjustment of the volume of cytoplasm per nucleus that the rates of mitosis will differ. 
Conidial apparatus. The conidia of Aspergillus nidulans, in contrast to the hyphae just described, are uninucleate, and diploid conidia have double the volume of haploid ones (Pontecorvo et al. 1953). It is of interest, therefore, to examine the structures lying between the multinucleate hyphae and the uninucleate conidia, i.e. the conidiophore which is coenocytic, and primary and secondary sterigmata which are uninucleate

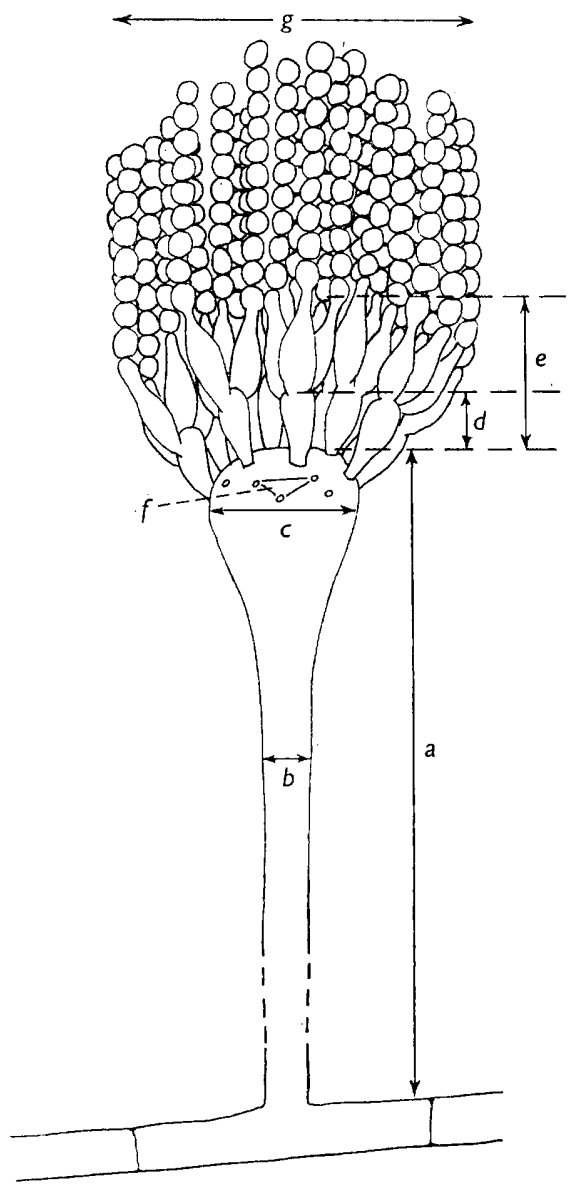

Fig. I. Diagram of a typical conidial head of Aspergillus nidulans. The lettering refers to parameters measured in Tables 2 and 4.

A conidial head is shown diagrammatically in Fig. I, along with the parameters whose dimensions are given in Tables 2 and 4. It can be seen from Table 2 that the multinucleate conidiophore resembles the hyphae in that its dimensions are independent of ploidy, while haploid and diploid sterigmata lengths are significantly different from one another. The sterigmata have also been tested to see whether their lengths differ by a factor of $\times \sqrt[3]{2}$; this would be the expected difference if the diploid sterigmata had double the volume of haploid ones and all their dimensions were increased proportionately to achieve this. Only the figures for the secondary sterigmata (obtained by subtraction) are in agreement with this hypothesis, the primary sterigmata differing by a considerably smaller factor. 
Following this result a study was made with the fluorescence microscope so that the nuclear state of the sterigmata could be related to size. Sterigmata form as buds on the vesicle. After repeated mitosis of the nuclei in the vesicle one nucleus migrates into each sterigma bud. Similarly, the secondary sterigmata form as buds on the primary sterigmata and are later provided with nuclei by division of the primary sterigma nuclei. Conidia then bud from the secondary sterigmata. To follow size changes during this process, total sterigma length was measured on 80 randomly chosen heads of haploid and diploid strains at each of the following stages: (I) primary sterigmata before entry of nuclei from the vesicle, (2) nucleated primary sterigmata, (3) primary plus secondary sterigmata before division of the nucleus, (4) primary plus secondary sterigmata where both are nucleated, (5) primary plus secondary sterigmata where these bear conidial buds.

Table 2. The dimensions of the conidial aparatus of Aspergillus nidulans

Dimensions in microns are given as means with standard errors. Letters $(a)-(e)$ refer to Fig. I.

Haploid

Diploid

Number of observations

Ratio: diploid/haploid*

' $t$ ' test: diploid $=$ haploid

' $t$ ' test: diploid $=\sqrt[3]{2} \times$

haploid

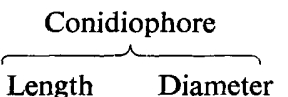

(a)

\begin{abstract}
Primary
sterigma length

(d)
\end{abstract}

(c)

$\begin{array}{cc}98 \cdot 8 \pm 4 \cdot 0 & 4.4 \pm 0 . I \\ 94.9 \pm 4.4 & 4.6 \pm 0.2 \\ 50 & 20 \\ 0.96 & I \cdot 05 \\ t=0.65 & t=0.60 \\ \text { Non-sig. } & \text { Non-sig. } \\ - & -\end{array}$

$$
\begin{gathered}
5.18 \pm 0.08 \\
5.54 \pm 0.08 \\
40 \\
I .07 \\
t=3.53 \\
P<0.001 \\
t=8.15 \\
P<0.001
\end{gathered}
$$

Total
sterigma
length
$(e)$

(e)

II. $52 \pm 0.10$
$13.69 \pm 0 \cdot 19$
40
$1 \cdot 19$
$t=10.4$
$P<0.001$
$t=3.68$
$P<0.001$

Secondary sterigma length (by subtraction)

* Where a diploid structure has double the volume of a haploid, its diameter or length is expected to differ by a factor of $\sqrt[3]{2}=\mathrm{I} \cdot 26$.

The results are combined in a histogram in Fig. 2. Only the mean of stage 5 is given since this is taken as the finishing point of sterigmata development. The differences between haploid and diploid may be obtained by estimating the position of boundaries between stages: an attempt to do this is shown by the arrows in Fig. 2. Alternatively, the variance may be taken as a measure of the spread of values in a stage, and hence of its duration (Table 3). Using the first method, the apparent elongation of stage I may well be an artifact of the sampling method, reflecting only the wider distribution of values of stage 2. All stages other than I, however, appear genuinely protracted. Both methods agree that the greatest increase occurs in stage 3 , although none of the variances differ significantly between the two strains. On the other hand, the means for all stages, again with the exception of the first, do differ signicantly between haploid and diploid. A difference between haploid and diploid means for a stage, however, cannot be interpreted exactly since it may be due to prolongation of that stage, or any of the previous ones.

In all, therefore, it appears that although diploid primary sterigmata are slightly larger than haploid ones, the main difference in volume does not arise until the stage when the secondary sterigmata are formed, but the nucleus has not yet divided.

Another character of the conidiophore has also been studied. This is the spacing of the primary sterigmata on the vesicle and is measured by the area of a 'sterigmata 
triangle' (Fig. I, $f$ ). It can be seen from Table 4 that this also is independent of ploidy. Taking it that the sterigmata cover the upper hemisphere of the vesicle, it can be calculated from the sterigmata triangle area and the diameter of the vesicle that the average conidial head, of either ploidy, bears 3I primary sterigmata. Since haploid and diploid

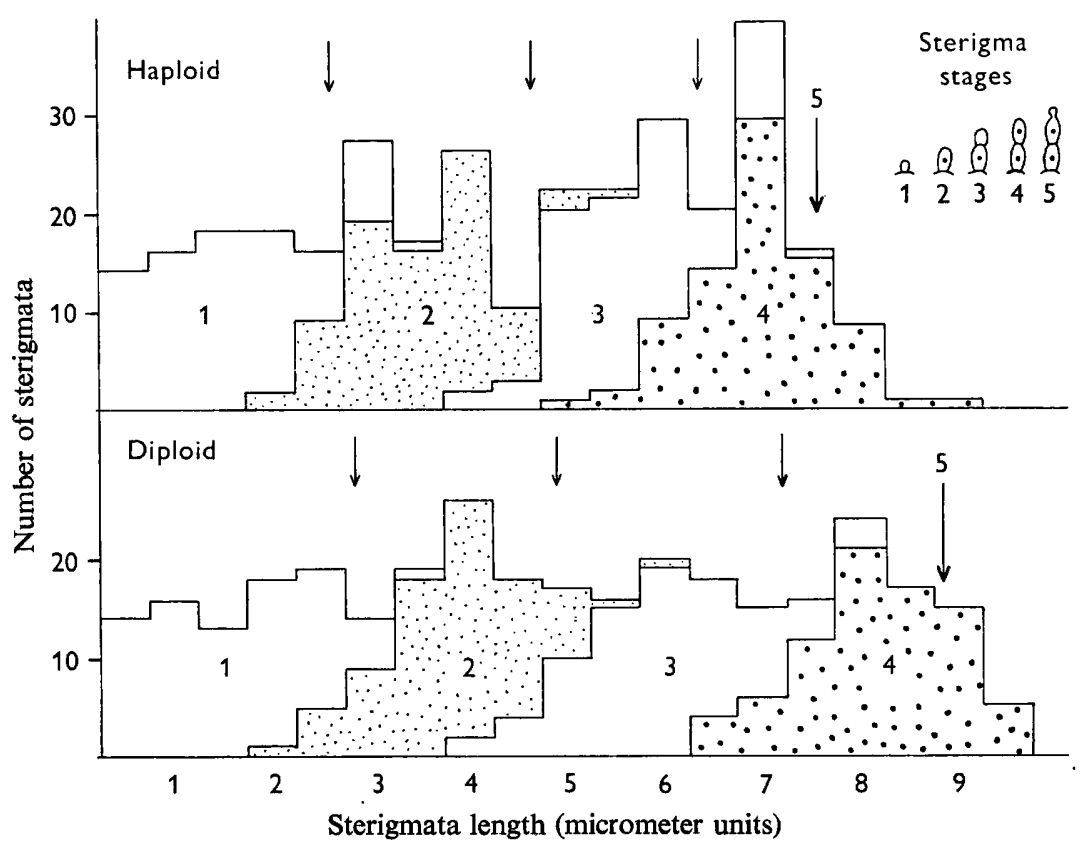

Fig. 2. Total sterigmata length in Aspergillus nidulans at various stages of development. The numbering of the histograms refers to the stages illustrated inset. I micrometer unit $=\mathrm{I} \cdot 57 \mu$.

Table 3. Aspergillus nidulans sterigmata length: tests of significance of the difference between haploid and diploid means and variances at the different stages of development shown in Fig. 2

\begin{tabular}{|c|c|c|c|c|}
\hline & $\begin{array}{l}\text { Stage I. } \\
\text { Anucleate } \\
\text { primary } \\
\text { sterigmata }\end{array}$ & $\begin{array}{l}\text { Stage } 2 . \\
\text { Nucleated } \\
\text { primary } \\
\text { sterigmata }\end{array}$ & $\begin{array}{c}\text { Stage } 3 . \\
\text { Primary } \\
\text { sterigmata plus } \\
\text { anucleate } \\
\text { secondary } \\
\text { sterigmata }\end{array}$ & $\begin{array}{c}\text { Stage } 4 . \\
\text { Primary plus } \\
\text { secondary } \\
\text { sterigmata both } \\
\text { nucleated }\end{array}$ \\
\hline $\begin{array}{l}\text { ' } t \text { ' test for difference } \\
\text { of means } \\
\text { Variance ratio: }\end{array}$ & $\begin{array}{l}t=0.33 \\
\text { Non-sig. } \\
1 \cdot 00\end{array}$ & $\begin{array}{l}t=3.04 \\
P<0.01 \\
\mathrm{I} .06\end{array}$ & $\begin{array}{l}t=2.27 \\
P<0.05 \\
\mathrm{I} \cdot \mathrm{I} 8\end{array}$ & $\begin{array}{l}t=10 \cdot 17 \\
P<0.001 \\
1 \cdot 09\end{array}$ \\
\hline
\end{tabular}

* To reach the $5 \%$ level of probability the variance ratio with $80 / 80$ degrees of freedom must exceed $1 \cdot 46$ (Fisher \& Yates, I963).

conidial heads bear the same numbers of primary sterigmata, and diploid conidia have twice the volume of haploid ones, it would be expected that the diameter of the tightly packed column of conidia would differ in the two ploidies by a factor of $\sqrt[3]{ } \times 2=1 \cdot 26$ 
The diameters differ but not to this extent (see Table 4). This is almost certainly related to the observation that in the diploid, but not in the haploid, some of the primary sterigmata fail to receive nuclei and therefore do not develop further. This would be expected to occur if the vesicle initially contained the same number of nuclei per unit volume as the hyphae: there would then be approximately 6 nuclei in the haploid vesicle and 3 in the diploid (taking the vesicle as a sphere). At least three rounds of division would then be required to provide nuclei for the sterigmata in the haploid, but this would be insufficient in the diploid. The actual numbers of nuclei in the vesicle cannot readily be determined due to the difficulty of identifying the stage before divisions begin, and thereafter, because of the tendency of a mass of nuclei stained by fluorescence to obscure one another.

\section{Table 4. The sterigmata triangle area and conidial column diameter in the conidial head of Aspergillus nidulans}

\begin{tabular}{|c|c|c|}
\hline & $\begin{array}{c}\text { Sterigmata triangle } \\
\text { area }\left(\mu^{2}\right) \\
(f)\end{array}$ & $\begin{array}{c}\text { Conidial column } \\
\text { diameter }(\mu) \\
(g)\end{array}$ \\
\hline Haploid & $2 \cdot 54 \pm 0.12$ & $46 \cdot 7 \pm 0 \cdot 9$ \\
\hline Diploid & $2 \cdot 60 \pm 0 \cdot 10$ & $50 \cdot 0 \pm I \cdot 0$ \\
\hline $\begin{array}{l}\text { Number of observations } \\
\text { ' } t \text { ' test: diploid = haploid }\end{array}$ & \begin{tabular}{l}
\multicolumn{1}{c}{50} \\
$t=0.48$ \\
Non-sig.
\end{tabular} & $\begin{array}{c}50 \\
t=2.47 \\
P<0.02\end{array}$ \\
\hline ' $t$ ' test: & & $t=6.03$ \\
\hline Diploid $=\sqrt[3]{2} \times$ haploid & - & $P<0.001$ \\
\hline Ratio: diploid/haploid* & $1 \cdot 02$ & $I \cdot 07$ \\
\hline
\end{tabular}

If the same number of cycles of division occurs in the vesicle in both ploidies, as suggested by this argument, then entry of nuclei into the primary sterigmata should occur at the same time. Since the primary sterigmata have been growing as extensions of the vesicle up to this point, and vesicle size is independent of ploidy, this may explain why the primary sterigmata do not differ before the nuclei enter.

The lack of difference is not made up once the nuclei have entered. This may mean that the interval of growth before budding is already determined at the time of entry of the nuclei into the primary sterigmata. This idea is supported by observations (Clutterbuck, unpublished) on a series of mutants designated 'aps' ('anucleate primary sterigmata') in which the nuclei fail to enter the primary sterigmata at all. In these strains, the anucleate sterigmata grow only slightly beyond the normal size at nuclear entry (achieving a final length of $4.96 \pm 0.08 \mu$ ), and then produce secondary buds that do not develop further. It is clear that in this case budding, but not growth, is possible in the absence of the nucleus.

Two hypotheses may be put forward to explain the dependence of cell volume on ploidy. The simpler postulates that there is a symbiotic type of relationship between nucleus and cytoplasm such that if either component is in excess its own growth is depressed while that of the other is stimulated. In such a system, a diploid nucleus would be able to support the same volume of cytoplasm as two haploid ones. Such a simple system would fit any of the data presented here. 
Bacterial work (Donachie \& Masters, 1968) suggests a more positive control system involving the triggering of DNA synthesis and cell division by critical ratios of cytoplasmic and nuclear components. A mechanism of this sort has also been proposed by Yčas et al. (1965). Mazia (196I) suggested that cell growth is dependent on the 'growth potential' that is released from the nucleus at certain stages of the cell cycle. In yeast this stage has been shown to be soon after budding (Mitchison, I958), possibly as a feature of the stepwise increase in enzyme levels that has now been shown in yeast (Tauro, Halvorson \& Epstein, 1968) as well as in bacteria (Masters \& Pardee, 1965). The similarity of the sterigmata of Aspergillus to the cells of budding yeasts suggests that a similar release of growth potential, of an amount proportional to ploidy, may occur some time after the entry of the nuclei into the primary sterigmata, and only at this time will the difference between diploids and haploids be fully expressed. This would provide an alternative explanation for the lack of difference between haploids and diploids at the primary sterigma stage.

This work was started at Sheffield University and I am grateful for the receipt of a Sheffield University Postgraduate Scholarship and for the help and interest of Professor J. A. Roper during that period.

I am equally indebted to Professor G. Pontecorvo, F.R.S., Dr B. L. Cohen and Dr D. A. Hopwood in Glasgow. I also wish to thank Mr M. J. Davies for statistical advice and Mr C. Mucci for drawing Fig. I.

\section{REFERENCES}

ANDERson, E. S., Armstrong, J. A. \& NIVEN, J. S. F. (I959). Fluorescence microscopy: observations of virus growth with aminoacridines. Symp. Soc. gen. Microbiol. 9, 224.

Clutterbuck, A. J. \& Roper, J. A. (1966). A direct determination of nuclear distribution in heterokaryons of Aspergillus nidulans. Genet. Res. Camb. 7, 185.

COMMONER, B. (1964). Roles of deoxyribonucleic acid in inheritance. Nature, Lond, 202, 960.

DonachIE, W. D. \& MAsters, M. (1968). In Cell Cycle. Gene Enzyme Interactions. Ed. I. L. Cameron G. M. Padilla and G. L. Whitson. New York and London: Academic Press (In the Press.)

Fisher, R. A. \& YATES, F. (1963). Statistical Tables, 6th Ed. Edinburgh and London: Oliver and Boyd Ltd.

Hartmann, M. (1928). Über experimentelle Unsterblichkeit von Protozoen-Individuen. Zool. $J b .45,973$.

Heagy, F. C. \& Roper, J. A. (1952). Deoxyribonucleic acid content of haploid and diploid Aspergillus conidia. Nature, Lond. 170, 713.

IsHTtAN, G., UCHIDA, K. \& IKEDA, K. (I956). The relation of DNA content to cell size in Aspergillus. Expl Cell Res. 10, 737.

KäFER, E. (1958). An 8-chromosome map of Aspergillus nidulans. Adv. Genet. 9, 105.

LIST, A. (1963). Some observations on DNA content and cell and nuclear volume growth in the developing xylem cells of certain higher plants. Am. J. Bot. 50, 320.

Masters, M. \& PARDEe, A. B. (1965). Sequence of enzyme synthesis and gene replication during the cell cycle of Bacillus subtilis. Proc. natn. Acad. Sci. U.S.A. 54, 64.

Mazia, D. (196I). Mitosis and the physiology of cell division. In The Cell. Ed. by J. Brachet and A. Mirsky, vol. 3. New York and London: Academic Press.

Mrtchison, J. M. (1958). The growth of single cells. II. Saccharomyces cerevisiae. Expl Cell Res. 15, 214.

NoGgLE, G. R. (1946). The physiology of polyploidy in plants. I. Review of the literature. Lloydia 9, I53.

Pontecorvo, G., Roper, J. A., Hemmons, L. M., Macdonald, K. D. \& Bufton, A. W. J. (1953). The genetics of Aspergillus midulans. Adv. Genet. 5, $14 \mathrm{I}$. 
PrescotT, D. M. (1956). Relation between cell growth and cell division. II. The effect of cell size on cell growth rate and generation time in Amoeba proteus. Expl Cell Res. II, 86.

ROPER, J. A. (1952). Production of heterozygous diploids in filamentous fungi. Experentia 8, 14.

SWANN, M. M. (1957). The control of cell division: a review. I. General mechanisms. Cancer Res. $17,727$.

Tauro, P., Halvorson, H. O. \& Epstein, R. L. (1968). Time of gene expression in relation to centromere distance during the cell cycle of Saccharomyces cerevisiae. Proc. natn. Acad. Sci. U.S.A. $59,277$.

YČAs, M., Sugrta, M. \& Bensam, A. (1965). A model of cell size regulation. J. theor. Biol. 9, 444. 